\title{
Nature Medicine - an international journal
}

When Nature Medicine was launched in January of 1995, it was with the clear objective of providing readers worldwide access to the very best biomedical research and accompanying analysis, news and comment. Circulation of the journal has climbed rapidly to 12,000 subscribers, whereas the monthly readership has been tributions to the biomedical research community and naturally - as we aspire to become the leading journal in this field - to the pages of Nature Medicine itself.

It is perhaps worth noting that Nature Medicine's success in Japan may be without precedent. That a new English language journal should be so swiftly and warmly embraced is probably in part due to the Japanese presence that Nature publishing has had now for many years. estimated as approaching 70,000 . Throughout this growth we have been committed to serving the international community by encouraging submissions from as far afield as possible, by establishing and expanding a global network of correspondents, by representing the opinions and concerns of readers worldwide and by delivering the journal to all our readers as quickly as possible. However, geography is a major hurdle to be overcome when distributing a journal to all four corners of the world, and inevitably, readers in Japan, and others in Asia Pacific, have had to wait longer for the journal to be delivered each month. Now, we are proud to extend our commltment to the international biomedical research community in a very significant way. As of April, Nature Medicine will-begin printing in Japan and, distribute these journals directly within Japan and to Korea.

Japan, the world's second largest economy, is a major center for biomedical research, and Japanese subscribers represent a full $25 \%$ of the total circulation of Nature Medicine. Recognizing the importance of this large and influential community, we are eager to ensure that our readers in Japan are not geographically handicapped by our printing in the United States. It is therefore our intention that Japanese readers get access to the journal at the same time as their international colleagues. By printing in Japan we will now be able to dispatch the journal to Japanese and Korean readers within the first week of each month (and for most readers in other parts of the world, on the first day of each month). Of course, this new capability will also put us in a good position to be vigilant of scientists and physicians in other parts of Asia that are currently undergoing tremendous economic development and expansion, in anticipation that the life sciences, including more clinically oriented research, will benefit from that development. It also recognizes that Japanese researchers have made significant and important con-
However, it is perhaps the rising interest in molecular medicine among young Japanese doctors that best explains our penetration of the Japanese biomedical research community. Also of importance are the unique pages added to the Japanese editions of Nature Medicine, offering a compendium, in Japanese, of the contents of each issue, including summaries of articles and editorial highlights. Although these added pages are clearly wellliked by Japanese readers, they should also come as welcomre news to all those published in Nature Medicine, who can rest assured that their work is reaching directly into the Japanese research community.

Neally ddecade ago our parent journal, Nature, took this same decision to print in Japan (and as a result, Nature Medicine can also boast the only Japanese office, which it shares with the other Nature titles, of any biomedical research journal). At that time it was suggested (see Nature 328, 97; 1987) that as Japan looked to improve its creative approach to science and technology, to complement its near legendary reputation as the fastest and most efficient applier of scientific knowledge, it would soon develop into one of the world's strongest research nations. The prophesy is reasonably fulfilled, as a glance through the top research journals will reveal. However, although a breakdown of the countries of origin of all the manuscripts received in our Washington editorial office shows that Nature Medicine is indeed an international journal, it has not escaped our notice that despite its very large readership, Japanese researchers are submitting - and having published - relatively few of the papers we receive. Thus we hope that our new venture in Japan will also encourage Japanese, and indeed other researchers throughout the world whose native tongue is not English, to contribute more readily to our pages and not to see a language barrier as a major impediment to submitting their best biomedical research and comment.

- Adrian J. Ivinson 